\title{
Colorectal Cancer Screening With Traditional and New-generation Fecal Immunochemical Tests: A Critical Review of Fecal Occult Blood Tests
}

\author{
JANNICA MEKLIN ${ }^{1}$, KARI SYRJÄNEN ${ }^{2,3}$ and MATTI ESKELINEN ${ }^{1}$ \\ ${ }^{1}$ Department of Surgery, Kuopio University Hospital and School of Medicine, \\ University of Eastern Finland, Kuopio, Finland; \\ ${ }^{2}$ Molecular Oncology of Research Center, Barretos Cancer Hospital, Barretos, Brazil; \\ ${ }^{3}$ SMW Consultants, Ltd., Kaarina, Finland
}

\begin{abstract}
Previous randomized studies suggest that fecal occult blood test (FOBT) screening can reduce mortality from colorectal cancer $(C R C)$. Our aim was to review the current status of FOBTs in CRC screening. FOB is measured using either the traditional guaiac-based tests or more recently introduced fecal immunochemical tests (FITs). FITs have several advantages over guaiac-based FOBTs, including higher sensitivity and specificity, resulting in improved clinical performance and higher efficiency. Another advantage in population screening according to European Guidelines for quality assurance in CRC screening is that FITs can be automated and user can adjust the cutoff at which a positive result is reported. In population-based screening, all those testing positively with any FOBT should be referred for colonoscopy. Conclusion: Although a plethora of FOBTs are available on the market, relatively few have been extensively tested for clinical sensitivity and specificity in CRC screening. Current data imply that new FITs have superior test characteristics as compared with guaiac-based FOBTs. The latest development in the field is represented by the proteomic-based tests that may further reduce false-negative rates in CRC screening. Simple stool
\end{abstract}

This article is freely accessible online.

Correspondence to: Matti Eskelinen, MD, Ph.D., School of Medicine, University of Eastern Finland, P.O. Box 100, FI-70029 Kuopio, Finland. Tel: +358 17173311, Fax: +358 17172611, GSM: +358 400969444, e-mail: matti.eskelinen@kuh.fi

Key Words: Colorectal cancer, diagnosis, screening, fecal occult blood test, FOBT, fecal immunochemical test, FIT, false-negative, false-positive, review. sample preservation and automatic analysis are other important issues in population-based screening for CRC.

Colorectal cancer (CRC) is the third most common cancer worldwide, with over 1.3 million new cases and over 600,000 deaths each year (1). In Finland, the incidence of CRC is lower than in many Western countries but mortality is quite similar, reflecting a mortality-to-incidence ratio disparity in Finland. During the 3-year period of 2015 to 2017, incident CRC was encountered in 4,577 women and in 5,131 in men, with an estimated annual average of 3,236 new CRC cases (2). After lung cancer, $\mathrm{CRC}$ is the second most common cause of cancer deaths among men and women combined in Finland (2).

The majority of CRCs develop from adenomas or adenomatous polyps and several studies have shown the efficacy of screening for detection of large adenomas. CRC screening can achieve the goals of both primary prevention (by detecting cancer precursors: polyps, adenomas) and secondary prevention (by detecting early cancers) $(3,4)$. Thus, organized CRC screening offers a possibility for cancer prevention and early detection of cancer, with reduced mortality $(5,6)$.

Although a plethora of fecal occult blood test (FOBT) are available on the market, relatively few of them have been extensively tested for clinical sensitivity and specificity in CRC screening. The main aim for the use of FOBTs is to reduce CRC mortality (7-11). European Guidelines for quality assurance in CRC screening recommend fecal immunochemical tests (FITs) because FITs have improved test characteristics compared to guaiac-based FOBTs (gFOBTs) (12) (Table I).

The most commonly used CRC screening tests include flexible sigmoidoscopy, colonoscopy and FOBT $(13,14)$. Lin et al. reviewed literature and found four randomized clinical trials (RCTs) evaluating one or two rounds of flexible sigmoidoscopy $(n=458,002)$, showing reduced 
Table I. Advantages and disadvantages of guaiac-based fecal occult blood test (gFOBT) compared with fecal immunochemical test (FIT) in colorectal cancer (CRC) screening (12).

\begin{tabular}{lcc}
\hline & gFOBT & FIT \\
\hline Diet & Dietary restriction & No restrictions \\
Stool sample instability & Stool sample instable & No sample instability $/$ keep cool $\left(+4^{\circ} \mathrm{C}\right)$ \\
Number of stool samples & Three or more & Fewer than three \\
Sensitivity for CRC & Low & Moderate $/$ high \\
Sensitivity for adenoma & Very low & Moderate \\
Specificity & Moderate & Moderate/high \\
Numerical cut-off for concentration & No & Yes \\
Automation of measurement & No & Yes \\
\hline
\end{tabular}

CRC-specific mortality compared with no screening [incidence rate ratio $=0.73 ; 95 \%$ confidence intervaI $(\mathrm{CI})=0.66-0.82]$. In addition, five RCTs with multiple rounds of biennial screening with gFOBTs $(n=419,966)$ showed reduced CRC-specific mortality [from relative risk $(\mathrm{RR})=0.91,95 \% \mathrm{CI}=0.84-0.98$ at 19.5 years to $\mathrm{RR}=0.78$, $95 \% \mathrm{CI}=0.65-0.93$ at 30 years from screening] (15).

gFOBTs have been the tests most often used in organized, population-based screening programs (16-18), and RCTs show that screening by FOBT can reduce CRC mortality by $18-33 \%(7,9,19)$. Two main types of FOBT exist: gFOBTs and FITs. The gFOBT uses the pseudoperoxidase activity of intact or free hemoglobin, based on the oxidation of guaiac by hydrogen peroxidase, and reacts with any peroxidase in feces. Therefore, the gFOBT test is not fully specific for human hemoglobin and the reaction is complicated by reaction of several foods with any peroxidase content, certain chemicals or medications $(20,21)$. On the other hand, the FIT detects early degradation products and the globin moiety of intact human hemoglobin (22-24). The gFOBT was the first technology on the market, and its clinical efficacy has been investigated more extensively than that of FITs (22-25). Because gFOBTs are not specific for human blood, it is necessary to confirm a FOBT-positive result by colonoscopy $(26,27)$.

Our aim in this article is to: i) Critically review the known limitations of gFOBT and FIT in CRC screening; and ii) introduce a modern genomics- and proteomics-based strategy for CRC screening.

\section{gFOBT}

Different gFOBTs have become very popular screening methods for CRC (15). The gFOBT has been on the market for several decades, and the test is quite easy to perform and inexpensive. In FOBTs, multiple samples are needed to detect CRC with high sensitivity. These tests detect FOB based on the peroxidase activity of hemoglobin-derived heme groups but, unfortunately, this reaction is not specific for human blood. In addition to human blood, these guaiac-based tests can also trace animal blood derived from food, and in addition, peroxidases derived from some raw vegetables. This can lead to false-positive results and unnecessary referrals for colonoscopy. In addition, these tests are not highly sensitive, which can also lead to false-negative results (15).

Several gFOBTs are available on the market with different sensitivity and specificity in detecting CRC $(28,29)$. Rabeneck et al. reviewed repeated annual or biennial gFOBT testing, showing gFOBT sensitivity for CRC from $51 \%$ to $100 \%$ and specificity from $90 \%$ to $97 \%$, with a positive predictive value of between $2.4 \%$ and $17.0 \%$ (28).

Although screening by gFOBTs has been shown to reduce mortality from CRC, the data on the efficacy of gFOBT screening are controversial (15). Hewitson et al. reviewed four RCTs, showing a $16 \%$ reduction in the RR of CRC mortality in the screened population ( $R R=0.84,95 \%$ $\mathrm{CI}=0.78-0.92$ ) (29). In the Minnesota trial, the RR was adjusted for attendance at screening, the overall predicted reduction in relative mortality was $25 \%$ amongst those screened ( $\mathrm{RR}=0.75,95 \% \mathrm{CI}=0.66-0.84)$ (7).

Although previous RCTs used the Hemoccult II test (Beckman, Fullerton, CA, USA), several non-randomized studies (30-33) used different gFOBTs, including Hemascreen (Immunostics, Ocean, NJ, USA). In conclusion, when critically assessed in a recent systematic review (15), a metaanalysis of all four FOBT screening trials indicated no benefit for all-cause mortality $(\mathrm{RR}=1.00,95 \% \mathrm{CI}=0.99-1.03)$ $(15,22)$. This made the authors suggest that it is not be expected that CRC screening would reduce all-cause mortality in these ongoing FOBT trials (15). In addition, because of their poor sensitivity and low specificity, gFOBTs have become increasingly replaced by FITs in populationbased CRC screening programs $(34,35)$.

\section{FITs}

Since the invention of the immunochemical test principle by Suovaniemi et al. in the 1980s (36), an increasing number of 
FITs have been developed, particularly in Japan, the pioneering country of CRC screening, where different FITs have been the principal screening method since the early 1990s (37). The FIT is based on the detection of the globin moiety of human hemoglobin or its degradation products. In a recent systematic review of FITs in CRC screening (21, 27), 12 types of FITs were identified in the literature, representing 20 different proprietary names. Due to the major differences in test methodology, the authors were unable to assess all FITs as a class, however, and undertook a sub-group analysis $(15,21)$. On the basis of a single stool specimen, the most commonly evaluated FITs demonstrated good sensitivity (range $=73 \%-88 \%$ ) and specificity (range $=90 \%-96 \%)$. Lin et al. reviewed one study $(n=9,989)$, reporting that FIT plus stool-based DNA test had better sensitivity $(92 \%)$ but lower specificity $(84 \%)$ in detecting CRC than FIT alone (15).

The only RCT comparing gFOBT and FIT published so far of van Rossum et al. concluded that the performance of FITs is clearly superior to that of gFOBTs in detecting any type of colorectal neoplasia (38). This has led to the rapid emergence of a large number of commercial FIT products onto the market. Lee et al. reviewed the accuracy of FITs for CRC screening and, after careful selection, they found 18 out of the 53 available studies to be eligible for their formal meta-analysis. These studies included eight different commercial FITs, but not the ColonView quick test (Biohit Oyj, Helsinki, Finland) because it was not yet on the market. In this meta-analysis, the pooled sensitivity and specificity for the CRC endpoint were: $79 \%$ $(95 \% \mathrm{CI}=69-86 \%)$ and $94 \% \quad(95 \% \quad \mathrm{CI}=93-97 \%)$, respectively (39). These meta-analytical results are supplemented by two separate studies testing ColonView in head-to-head comparison with gFOBT (Hemoccult SENSA; Beckman Coulter, Pasadena, Los Angeles, CA, USA) $(26,27)$. In a St. Petersburg study of a cohort of 300 patients referred for colonoscopy, the ColonView test showed pooled sensitivity of $100 \%$ and specificity of $95 \%$ for proximal colon neoplasia as well as $98 \%$ sensitivity and $95 \%$ specificity for distal colon neoplasia (26). Guimarães et al. conducted a clinical trial comparing the ColonView test with gFOBT in a similar setting of 368 colonoscopy-referral patients at Barretos Cancer Hospital in Brazil. For the CRC endpoint, the ColonView test had $95 \%$ sensitivity and $65 \%$ specificity [area under the receiver operating characteristics curve (AUC) $=0.799$ ], while the gFOBT had sensitivity of $76 \%$ and specificity of $84 \%$ (AUC=0.800). For the adenoma endpoint, the difference in sensitivity between ColonView test and gFOBT was even larger (sensitivity of $44 \%$ versus $19 \%$, respectively). The authors concluded that due to its $95 \%$ sensitivity, ColonView test is superior to gFOBT in organized CRC screening (27).

\section{Genomics and Proteomics-based Approaches in CRC Screening}

Compared with gFOBTs and iFOBTs, the use of genomicsand proteomics-based approaches in population-based CRC screening has been less widely investigated. The aim in using fecal DNA markers in CRC screening is to find mutant DNA present in stool. Imperiale et al. investigated a DNA panel of 21 separate mutations in several tumor protein genes, as well as the detection of microsatellite markers. They concluded that the DNA marker panel displayed a higher sensitivity than the gFOBT, without a marked reduction in specificity. However, the gFOBT result was based on only a test from a single time point (40).

Ahlquist et al. investigated the same DNA panel with two different gFOBTs in a multi-center study of 2,497 asymptomatic individuals; the sensitivity for CRC was $20 \%$ for the DNA test, $11 \%$ for Hemoccult II and $21 \%$ for Hemoccult SENSA specificity was $96 \%$ for the DNA panel, 98\% for Hemoccult and $97 \%$ for Hemoccult SENSA (41).

RNA-based CRC screening methods may offer a more promising strategy than use of fecal DNA markers alone (4246). A microRNA strategy might meet the criteria of an optimal CRC screening test: It is non-invasive; $1 \mathrm{~g}$ of stool is adequate for testing; sampling on consecutive dates is not required; stool samples can be sent by mail; the test is able to differentiate between normal tissue and CRC; and the test can be automated (47). In their first article, Ahmed et al. addressed the experimental design and selected 10 colon cancer genes to monitor changes at various stages in the neoplastic process particularly applicable for screening of early-stage CRC. Although some of the genes in CRC tissue showed less variability, stool, however, was suitable for CRC screening and the so-called transcriptomic molecular strategy using tissue or stool samples offerred higher sensitivity and specificity than currently used DNA markers (42). In their second article, the same authors described the standardization strategy and test performance of transcriptomic molecular markers in CRC screening. The preservation of stool samples prior to RNA extraction is important, and use of an appropriate preservative and keeping the stool at $4^{\circ} \mathrm{C}$ during transport is recommended (43). Total RNA extraction kits are commercially available, containing buffer which removes bacterial RNA from stool samples, leaving the undegraded RNA of human origin.

In order to determine the sensitivity and specificity of transcriptomic CRC screening, it is important to conduct prospective RCTs. In 2014, in studying 41 patients with CRC and 54 healthy controls, Koga et al. demonstrated that a highly sensitive DNA chip assay had higher sensitivity and specificity in detecting early-stage CRC (48).

Since sporadic CRC is one of the most frequent types of cancer in Western world, a large number of other biomarkers 
and analyses are available to predict disease prognosis and to help in CRC screening (46, 49-54). Auge et al. used a compact fully-automated immunochemistry analyzer (Kroma It; Linear Chemicals S. L. Spain, distributed in Spain by Laboratorios LETI, S. L. Unipersonal, Spain) for fecal occult hemoglobin, with sensitivity and specificity for CRC of $36 \%$ and 92\%, respectively (49). Christensen et al. (50) determined plasma TIMP metallopeptidase inhibitor 1 (TIMP1) and carcinoembryonic antigen (CEA) as markers for CRC using an automated analysis platform. Due to the small number of patients with CRC $(n=32)$, sensitivity and specificity were not reported but the AUC was 0.731 for CEA, 0.695 for TIMP1, and 0.753 for CEA combined with TIMP1. Dressen et al. evaluated the diagnostic performance of a new magnetic multiplex immunoassay including several biomarkers for CRC diagnosis. CEA showed the best performance, with an AUC of 0.859. A combination of CEA and cancer antigen 19-9 had a higher AUC (0.893) as compared to either biomarker alone. They concluded that CRC diagnosis could be improved by a new biomarker classes and their combination by novel multiplex immunoassay (51). Bruns-Toepler et al. evaluated a new stool sample collection device with increased buffer stability for FIT, being a particularly promising tool for large-scale screening of CRC due to its advanced properties in sample handling, stability and hemaglobin analysis (52). Venäläinen et al. used urinary metabolomics to identify a panel of polyamine profiles for detecting CRC. They concluded that the determination of urinary polyamines by liquid chromatography-mass spectrometry can be used to differentiate those with CRC from healthy individuals (53).

\section{Conclusions and Relevance - Which Fecal Test Should Be Chosen in CRC Screening?}

There is little doubt that the characteristics of the FITs are superior to those of gFOBT as the screening tool for CRC (12; Table I). The WHO Guidelines recommend a panel of gFOBT and FIT (22). This strategy has been studied using an approach in which those with a weakly positive or equivocal result on gFOBT were asked to complete a FIT with a tube and a card collection device $(55,56)$. This strategy may reduce the number of false-positive results in CRC screening.

European Guidelines for quality assurance in CRC screening recommend FIT tests because FITs have improved test characteristics compared to gFOBTs (12). FITs have higher sensitivity and specificity, can be automated and the user can adjust the cut-off at which a positive result is reported. In conclusion, FITs are currently the test of choice for population-based CRC screening (Table I).

The latest development in the field of CRC screening is represented by genomics- and proteomics-based approaches, both of which have been less intensely studied. The strategy of using fecal DNA markers in CRC screening is based on the finding that mutant DNA is excreted in stool. At present, RNA-based methods look more promising than the use of fecal DNA markers only. Of the latter, a miRNA strategy seems to be among the most optimal for CRC in the future.

\section{Conflicts of Interest}

The Authors report no conflicts of interest or financial ties to disclose. The Authors alone are responsible for the content and writing of this article.

\section{Authors' Contributions}

All Authors have met all of the following four criteria: i). Substantial contributions to the conception or design of the work or the acquisition, analysis, or interpretation of data for the work. ii). Drafting the work or revising it critically for important intellectual content. iii). Final approval of the version to be published. iv). Agreement to be accountable for all aspects of the work in ensuring that questions related to the accuracy or integrity of any part of the work are appropriately investigated and resolved.

\section{Acknowledgements}

The study was funded by the Heikki, Aino and Aarne Korhonen foundation and the EVO-funding of the Kuopio University Hospital, Finland.

\section{References}

1 Ferlay J, Soerjomataram I, Dikshit R, Eser S, Mathers C, Rebelo M, Parkin DM, Forman D and Bray F: Cancer incidence and mortality worldwide: sources, methods and major patterns in GLOBOCAN. Int J Cancer 136: E359-386, 2012. PMID: 25220842. DOI: $10.1002 / \mathrm{ijc} .29210$

2 Suomen Syöpärekisteri. Available at: http://www.cancer.fi/ syoparekisteri/

3 Shussman N and Wexner SD: Colorectal polyps and polyposis syndromes. Gastroenterology Rep 2: 1-15, 2014. PMID: 24760231. DOI: $10.1093 /$ gastro/got041

4 Ponugoti PL, Cummings OW and Rex DK: Risk of cancer in small and diminutive colorectal polyps. Dig Liver Dis 49: 3437, 2017. PMID: 27443490. DOI: 10.1016/j.dld.2016.06.025

5 Towler B, Irwig L, Glasziou P, Kewenter J, Weller D and Silagy $\mathrm{C}$ : A systematic review of the effects of screening for colorectal cancer using the faecal occult blood test, hemoccult. BMJ 317: 559-565, 1998. PMID: 9721111. DOI: 10.1136/bmj.317.7158.559

6 Elmunzer BJ, Hayward RA, Schoenfeld PS, Saini SD, Deshpande A and Waljee AK: Effect of flexible sigmoidoscopybased screening on incidence and mortality of colorectal cancer: A systematic review and meta-analysis of randomized controlled trials. PLoS Med 9: e1001352, 2012. PMID: 23226108. DOI: 10.1371/journal.pmed.1001352

7 Mandel JS, Bond JH, Church TR, Snover DC, Bradley GM, Schuman LM and Ederer F: Reducing mortality from colorectal cancer by screening for fecal occult blood. Minnesota Colon 
Cancer Control Study. N Engl J Med 328: 1365-1371, 1993. PMID: 8474513. DOI: 10.1056/NEJM199305133281901

8 Kewenter J, Brevinge H, Engaras B, Haglind E and Ahrén C: Results of screening, rescreening, and follow-up in a prospective randomized study for detection of colorectal cancer by fecal occult blood testing. Results for 68,308 subjects. Scand J Gastroenterology 29: 468-473, 1994. PMID: 8036464. DOI: $10.3109 / 00365529409096840$

9 Kronborg O, Fenger C, Olsen J, Jørgensen OD and Søndergaard $\mathrm{O}$ : Randomised study of screening for colorectal cancer with faecal-occult-blood test. Lancet 348: 1467-1471, 1996. PMID: 8942774. DOI: 10.1016/S0140-6736(96)03430-7

10 Hardcastle JD, Chamberlain JO, Robinson JH, Moss SM, Amar SS, Balfour TW, James PD and Mangham CM: Randomised controlled trial of faecal occult blood screening for colorectal cancer. Lancet 348: 1472-1477, 1996. PMID: 8942775. DOI: 10.1016/S0140-6736(96)03386-7

11 Lindholm E, Brevinge $\mathrm{H}$ and Haglind E: Survival benefit in a randomized clinical trial of faecal occult blood screening for colorectal cancer. Br J Surg 95: 1029-1036, 2008. PMID: 18563785. DOI: $10.1002 /$ bjs.6136

12 Halloran S, Launoy G and Zappa M: Faecal Occult Blood Testing. In: European Guidelines for Quality Assurance in Colorectal Cancer Screening and Diagnosis. Segnan N, Patrick $\mathrm{J}$ and von Karsa L (eds.). Luxemburg: Publications Office of the European Union, pp. 103-144, 2010.

13 Rex DK, Boland CR, Dominitz JA, Giardiello FM, Johnson DA, Kaltenbach T, Levin TR, Lieberman D and Robertson DJ: Colorectal cancer screening: Recommendations for physicians and patients from the U.S. multi-society task force on colorectal cancer. Gastroenterology 153: 307-323, 2017. PMID: 28600072. DOI: $10.1053 /$ j.gastro.2017.05.013

14 Inadomi JM: Screening for colorectal neoplasia. N Engl J Med 376: 1599-1600, 2017. PMID: 28423294. DOI: 10.1056/ NEJMc 1702535

15 Lin JS, Piper MA, Perdue LA, Rutter CM, Webber EM, O'Connor E, Smith N and Whitlock EP: Screening for colorectal cancer: Updated evidence report and systematic review for the US Preventive Services Task Force. JAMA 315: 2576-2594, 2016. PMID: 27305422. DOI: 10.1001/jama.2016.3332

16 Lee TJ1, Clifford GM, Rajasekhar P, Rutter MD, Kometa S, Ritchie MC, Waddup G, Nylander D, McNally RJ and Rees CJ: High yield of colorectal neoplasia detected by colonoscopy following a positive faecal occult blood test in the NHS Bowel Cancer Screening Programme. J Med Screen 18: 82-86, 2011. PMID: 21852700. DOI: 10.1258/jms.2011.011032

17 Chiu HM, Ching JY, Wu KC, Rerknimitr R, Li J, Wu DC, Goh KL, Matsuda T, Kim HS, Leong R, Yeoh KG, Chong VH, Sollano JD, Ahmed F, Menon J and Sung JJ; Asia-Pacific Working Group on Colorectal Cancer: A risk-scoring system combined with a fecal immunochemical test is effective in screening high-risk subjects for early colonoscopy to detect advanced colorectal neoplasms. Gastroenterology 150: 617-625.e3, 2016. PMID: 26627608. DOI: $10.1053 /$ j.gastro.2015.11.042

18 Toes-Zoutendijk E, van Leerdam ME, Dekker E, van Hees F, Penning C, Nagtegaal I, van der Meulen MP, van Vuuren AJ, Kuipers EJ, Bonfrer JMG, Biermann K, Thomeer MGJ, van Veldhuizen H, Kroep S, van Ballegooijen M, Meijer GA, de Koning HJ, Spaander MCW and Lansdorp-Vogelaar I; Dutch National Colorectal Cancer Screening Working Group: Real-time monitoring of results during first year of dutch colorectal cancer screening program and optimization by altering fecal immunochemical test cut-off levels. Gastroenterology 152: 767-775.e2, 2017. PMID: 27890769. DOI: $10.1053 /$ j.gastro.2016.11.022

19 Scholefield JH, Moss SM, Mangham CM, Whynes DK and Hardcastle JD: Nottingham trial of faecal occult blood testing for colorectal cancer: A 20-year follow-up. Gut 61: 1036-1040, 2012. PMID: 22052062. DOI: 10.1136/gutjnl-2011-300774

20 Whitlock EP, Lin J, Liles E, Beil T, Fu R, O'Connor E, Thompson RN and Cardenas T: Screening for colorectal cancer: An updated systematic review. Evidence Synthesis No. 65, Part 1. AHRQ Publication No. 08-05124-EF-1. Rockville, Maryland, Agency for Healthcare Research and Quality, October 2008.

21 Whitlock EP, Lin JS, Liles E, Beil TL and Fu R: Screening for colorectal cancer: An updated systematic review for the US Preventive Services Task Force. Ann Intern Med 149: 638-658, 2008. PMID: 18838718. DOI: 10.7326/0003-4819-149-9200811040-00245

22 Allison JE, Tekawa IS, Ransom LJ and Adrain AL: A comparison of fecal occult-blood tests for colorectal-cancer screening. N Engl J Med 334: 155-159, 1996. PMID: 8531970. DOI: $10.1056 /$ NEJM199601183340304

23 Young GP, St John DJ, Winawer SJ and Rozen P; WHO (World Health Organization) and OMED (World Organization for Digestive Endoscopy): Choice of fecal occult blood tests for colorectal cancer screening: recommendations based on performance characteristics in population studies: A WHO (World Health Organization) and OMED (World Organization for Digestive Endoscopy) report. Am J Gastroenterology 97: 2499-2507, 2002. PMID: 12385430. DOI: 10.1111/j.1572-0241.2002.06046.x

24 Kahi CJ, Rex DK and Imperiale TF: Screening, surveillance, and primary prevention for colorectal cancer: A review of the recent literature. Gastroenterology 135: 380-399, 2008. PMID: 18582467. DOI: $10.1053 /$ j.gastro.2008.06.026

25 Huang CS, Lal SK and Farraye FA: Colorectal cancer screening in average risk individuals. Cancer Causes Control 16: 171-188, 2005. PMID: 15868457. DOI: 10.1007/s10552-004-4027-z

26 Vasilyev S, Smirnova E, Popov D, Semenov A, Eklund C, Hendolin P, Paloheimo L and Syrjänen K: A new-generation fecal immunochemical test (FIT) is superior to quaiac-based test in detecting colorectal neoplasia among colonoscopy referral patients. Anticancer Res 35: 2873-2880, 2015. PMID: 25964570.

27 Guimarães DP, Fregnani JH, Reis RM, Taveira LN, Scapulatempo-Neto C, Matsushita M, Silva SRM, Oliveira CZ, Longatto-Filho A, Eklund C, Paloheimo L, Mauad E, Suovaniemi $\mathrm{O}$ and Syrjänen K: Comparison of a new-generation fecal immunochemical test (FIT) with guaiac fecal occult blood test (gFOBT) in detecting colorectal neoplasia among colonoscopy-referral patients. Anticancer Research 39: 261-269, 2019. PMID: 30591467. DOI: 10.21873/anticanres.13106

28 Rabeneck L, Zwaal C, Goodman JH, Mai V and Zamkanei M: Cancer Care Ontario guaiac fecal occult blood test (FOBT) laboratory standards: Evidentiary base and recommendations. Clin Biochem 41: 1289-1305, 2008. PMID: 18796300. DOI: 10.1016/j.clinbiochem.2008.08.069

29 Hewitson P, Glasziou P, Watson E, Towler B and Irwig L: Cochrane systematic review of colorectal cancer screening using the fecal occult blood test (hemoccult): An update. Am J Gastroenterology 103: 1541-1549, 2008. PMID: 18479499. DOI: $10.1111 /$ j.1572-0241.2008.01875.x 
30 Faivre J, Dancourt V, Lejeune C, Tazi MA, Lamour J, Gerard D, Dassonville F and Bonithon-Kopp C: Reduction in colorectal cancer mortality by fecal occult blood screening in a French controlled study. Gastroenterology 126: 1674-1680, 2004. PMID: 15188160. DOI: 10.1053/j.gastro.2004.02.018

31 UK Colorectal Cancer Screening Pilot Group: Results of the first round of a demonstration pilot of screening for colorectal cancer in the United Kingdom. Br Med J 329: 133-135, 2004. PMID: 15237087. DOI: 10.1136/bmj.38153.491887.7C

32 Malila N, Oivanen T, Malminiemi O and Hakama M: Test, episode, and programme sensitivities of screening for colorectal cancer as a public health policy in Finland: experimental design. BMJ 337: a2261, 2008. PMID: 19022840. DOI: 10.1136/ bmj.a2261

33 Steele RJ, McClements PL, Libby G, Black R, Morton C, Birrell J, Mowat NA, Wilson JA, Kenicer M, Carey FA and Fraser CG: Results from the first three rounds of the Scottish demonstration pilot of FOBT screening for colorectal cancer. Gut 58: 530-535, 2009. PMID: 19036949. DOI: 10.1136/gut.2008.162883

34 Rabeneck L, Rumble RB, Thompson F, Mills M, Oleschuk C, Whibley A, Messersmith $\mathrm{H}$ and Lewis N: Fecal immunochemical tests compared with guaiac fecal occult blood tests for population-based colorectal cancer screening. Can J Gastroenterology 26: 131-147, 2012. PMID: 22408764. DOI: $10.1155 / 2012 / 486328$

35 US Preventive Services Task Force, Bibbins-Domingo K, Grossman DC, Curry SJ, Davidson KW, Epling JW Jr, García FAR, Gillman MW, Harper DM, Kemper AR, Krist AH, Kurth AE, Landefeld CS, Mangione CM, Owens DK, Phillips WR, Phipps MG, Pignone MP and Siu AL: Screening for colorectal cancer: US Preventive Services Task Force Recommendation Statement. JAMA 315: 2564-2575, 2016. PMID: 27304597. DOI: $10.1001 /$ jama.2016.5989

36 Suovaniemi O: Immunoassay for fecal human hemoglobin. Available at: https://patents.google.com/patent/US4427769

37 Sung J: Colorectal cancer screening: Its time for action in Asia Editorial. Cancer Detect Prev 31: 1-2, 2007. PMID: 17339084. DOI: $10.1016 /$ j.cdp.2007.01.002

38 van Rossum LG, van Rijn AF, Laheij RJ, van Oijen MG, Fockens P, van Krieken HH, Verbeek AL, Jansen JB and Dekker E: Random comparison of guaiac and immunochemical fecal occult blood tests for colorectal cancer in a screening population. Gastroenterology 135: 82-90, 2008. PMID: 18482589. DOI: $10.1053 /$ j.gastro.2008.03.040

39 Lee JK, Liles EG, Bent S, Levin TR and Corley DA: Accuracy of fecal immunochemical tests for colorectal cancer: Systematic review and meta-analysis. Ann Intern Med 160: 171, 2014. PMID: 24658694. DOI: 10.7326/M13-1484

40 Imperiale T, Ransohoff D, Itzkowitz SH, Turnbull BA and Ross ME; Colorectal Cancer Study Group: Fecal DNA versus fecal occult blood for colorectal-cancer screening in an average risk population. N Engl J Med 351: 2704-2714, 2004. PMID: 15616205. DOI: 10.1056/NEJMoa033403

41 Ahlquist DA, Sargent DJ, Loprinzi CL, Levin TR, Rex DK, Ahnen DJ, Knigge K, Lance MP, Burgart LJ, Hamilton SR, Allison JE, Lawson MJ, Devens ME, Harrington JJ and Hillman SL: Stool DNA and occult blood testing for screen detection of colorectal neoplasia. Ann Int Med 149: 441-450, 2008. PMID: 18838724. DOI: 10.7326/0003-4819-149-7200810070-00004
42 Ahmed FE, Vos P, James S, Lysle DT, Allison RR, Flake G, Sinar DR, Naziri W, Marcuard SP and Pennington R: Transcriptomic molecular markers for screening human colon cancer in stool and tissue. Cancer Genomics Proteomics 4: 1-20, 2007. PMID: 17726236

43 Ahmed FE, Vos PW, Ijames S, Lysle DT, Flake G, Sinar DR, Naziri W and Marcuard SP: Standardization for transcriptomic molecular markers to screen human colon cancer. Cancer Genomics Proteomics 4: 419-431, 2007. PMID: 18204205.

44 Ahmed FE, Jeffries CD, Vos PW, Flake G, Nuovo GJ, Sinar DR, Naziri W and Marcuard SP: Diagnostic microRNA markers for screening sporadic human colon cancer and active ulcerative colitis in stool and tissue. Cancer Genomics Proteomics 6: 281295, 2009. PMID: 19996134

45 Ahmed FE, Amed NC, Vos PW, Bonnerup C, Atkins JN, Casey M, Nuovo GJ, Naziri W, Wiley JE and Allison RR: Diagnostic microRNA markers to screen for sporadic human colon cancer in blood. Cancer Genomics Proteomics 9: 179-192, 2012. PMID: 22798503.

46 González-González M, Garcia JG, Montero JA, Fernandez LM, Bengoechea O, Muñez OB, Orfao A, Sayagues JM and Fuentes M: Genomics and proteomics approaches for biomarker discovery in sporadic colorectal cancer with metastasis. Cancer Genomics Proteomics 10: 19-25, 2013. PMID: 23382583.

47 Ahmed FE, Ahmed NC, Vos PW, Bonnerup C, Atkins JN, Casey M, Nuovo GJ, Naziri W, Wiley JE, Mota $\mathrm{H}$ and Allison RR: Diagnostic microRNA markers to screen for sporadic human colon cancer in stool: I. Proof of principle. Cancer Genomics Proteomics 10: 93-113, 2013. PMID: 23741026.

48 Koga Y, Yamazaki N, Takizawa S, Kawauchi J, Nomura O, Yamamoto S, Saito N, Kakugawa Y, Otake Y, Matsumoto M and Matsumura Y: Gene expression analysis using a highly sensitive DNA microarray for colorectal cancer screening. Anticancer Research 34: 169-176, 2014. PMID: 24403458.

49 Auge JM, Rodriguez C, Pellise M, Bernal A, Grau J, Castells A, Filella X and Molina R: Analytical and clinical performance of Kroma iT, a compact fully-automated immunochemistry analyzer for fecal occult hemoglobin. Anticancer Res 33: 56335637, 2013. PMID: 24324109.

50 Christensen IJ, Brünner N, Dowell B, Davis G, Nielsen HJ, Newstead G and King D: Plasma TIMP1 and CEA as markers for detection of primary colorectal cancer: A prospective validation study including symptomatic and non-symptomatic individuals. Anticancer Res 35: 4935-4941, 2015. PMID: 26254391.

51 Dressen K, Hermann N, Manekeller S, Walgenbach-Bruenagel G, Schildberg FA, Hettwer K, Uhlig S, Kalff JC, Hartmann G and Holdenrieder S: Diagnostic performance of a novel multiplex immunoassay in colorectal cancer. Anticancer Res 37: 2477-2486, 2017. PMID: 28476816. DOI: 10.21873/anticanres. 11588

52 Bruns-Toepler $\mathrm{M}$ and Hardt P: Evaluation of a new technique for iFOBT Utilising a new sample collection device with increased buffer stability. Anticancer Res 37: 3735-3740, 2017. PMID: 28668868. DOI: 10.21873/anticanres.11747

53 Venäläinen MK, Roine AN, Häkkinen MR, Vepsäläinen JJ, Kumpulainen PS, Kiviniemi MS, Lehtimäki T, Oksala NK and Rantanen TK: Altered polyamine profiles in colorectal cancer. Anticancer Res 38: 3601-3607, 2018. PMID: 29848716. DOI: 10.21873/anticanres.12634 
54 Ahmed FE, Gouda MM, Hussein LA, Ahmed NC, Vos PW and Mohammad MA: Role of melt curve analysis in interpretation of nutrigenomics microRNA expression data. Cancer Genomics Proteomics 14: 469-481, 2017. PMID: 29109097. DOI: $10.21873 / \operatorname{cgp} .20057$

55 Fraser CG, Matthew CM, Mowat NAG, Wilson JA, Carey FA and Steele RJ: Immunochemical testing of individuals positive for guaiac faecal occult blood test in a screening programme for colorectal cancer: An observational study. Lancet Oncology 7: 127-131, 2006. PMID: 16455476. DOI: 10.1016/S14702045(05)70473-3
56 Fraser CG, Mathew CM, Mowat NAG, Wilson JA, Carey FA and Steele RJ: Evaluation of a card collection-based faecal immunochemical test in screening for colorectal cancer using a two-tier reflex approach. Gut 56: 1415-1418, 2007. PMID: 17309886. DOI: $10.1136 /$ gut.2007.119651

Received January 8, 2020

Revised January 15, 2020

Accepted January 16, 2020 